\title{
Expanding the Spectrum of Light-Driven Peroxygenase Reactions
}

\author{
Sébastien J.-P. Willot, ${ }^{\dagger}$ Elena Fernández-Fueyo, ${ }^{\dagger}$ Florian Tieves, ${ }^{\dagger}$ Milja Pesic, ${ }^{\dagger}$ Miguel Alcalde, ${ }^{\ddagger}$ \\ Isabel W.C.E. Arends, ${ }^{\S}$ Chan Beum Park, ${ }^{\| \odot}$ and Frank Hollmann* ${ }^{\dagger}{ }^{\dagger}$
}

${ }^{\dagger}$ Department of Biotechnology, Delft University of Technology, van der Maasweg 9, 2629 HZ Delft, The Netherlands

${ }^{\ddagger}$ Department of Biocatalysis, Institute of Catalysis, CSIC, 28049 Madrid, Spain

${ }^{\S}$ Faculty of Science, University of Utrecht, 3584 CD Utrecht, The Netherlands

"Department of Materials Science and Engineering, Korea Advanced Institute of Science and Technology (KAIST), 335 Science Road, Daejeon 305-701, Republic of Korea

\section{Supporting Information}

ABSTRACT: Peroxygenases require a controlled supply of $\mathrm{H}_{2} \mathrm{O}_{2}$ to operate efficiently. Here, we propose a photocatalytic system for the reductive activation of ambient $\mathrm{O}_{2}$ to produce $\mathrm{H}_{2} \mathrm{O}_{2}$ which uses the energy provided by visible light more efficiently based on the combination of wavelength-complementary photosensitizers. This approach was coupled to an enzymatic system to make formate available as a sacrificial electron donor. The scope and current limitations of this approach are reported and discussed.

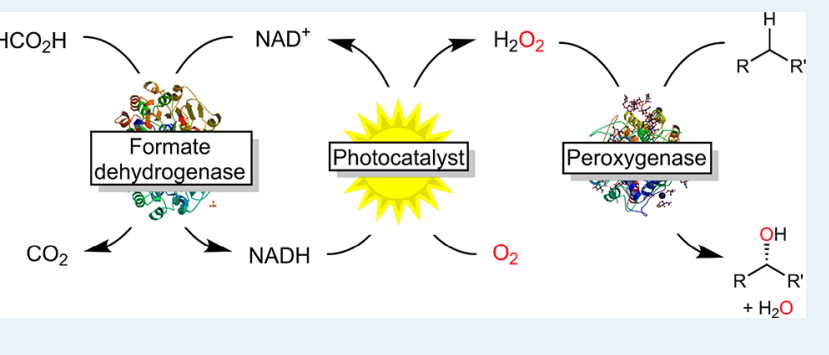

KEYWORDS: biocatalysis, formate dehydrogenase, hydrogen peroxide formation, oxyfunctionalization, peroxygenases, photocatalysis

$\mathrm{P}$ eroxygenases are receiving tremendous interest as catalysts for selective oxyfunctionalization reactions. ${ }^{1-3}$ Compared to the well-known P450 monooxygenases, peroxygenases exhibit a comparable reactivity pattern as both rely on an oxyferryl species (Compound I) as catalytically active compound. To generate Compound I, P450 monooxygenases rely on complicated electron transport chains while peroxygenases require only hydrogen peroxide.

Nevertheless, peroxygenases are rapidly inactivated in the presence of even small concentrations of $\mathrm{H}_{2} \mathrm{O}_{2}$. The peroxygenase from Caldariomyces fumago, for example, exhibits a half-life time of $38 \mathrm{~min}$ in the presence of $50 \mu \mathrm{M} \mathrm{H}_{2} \mathrm{O}_{2}{ }^{4}$ Therefore, careful control of the in situ $\mathrm{H}_{2} \mathrm{O}_{2}$ concentration is required. Slow addition of $\mathrm{H}_{2} \mathrm{O}_{2}$ is possible but results in significant dilution of the reaction mixtures. More elegantly, $\mathrm{H}_{2} \mathrm{O}_{2}$ is generated within the reaction mixture through reduction of ambient molecular oxygen. For example, enzymatic $\mathrm{H}_{2} \mathrm{O}_{2}$ generation systems have been developed. ${ }^{5-8}$ More recently, also electrochemical ${ }^{4,9-12}$ and photocatalytic alternatives have moved into the focus. ${ }^{13-18}$ The latter bear the promise of utilizing sunlight as a thermodynamic driving force to promote selective oxyfunctionalization reactions. Today, however, these systems suffer from some major drawbacks such as formation of large (and toxicologically and environmentally questionable) amounts of waste (Table S4) ${ }^{16-18}$ or sluggish reaction kinetics. ${ }^{13,14}$ Also, so far, only flavin- or $\mathrm{TiO}_{2}$ based photocatalysts have been used, limiting the wavelength range to the near UV and blue light $(450 \mathrm{~nm})$. Hence, only a fraction of wavelengths is used, leaving a significant amount of sunlight energy unexploited.
In this study, we aimed at addressing both issues and provide the proof-of-concept for more efficient photocatalytic oxyfunctionalization reactions. We envisioned using simple formate as a sacrificial electron donor, producing $\mathrm{CO}_{2}$ as stoichiometric byproduct. Furthermore, by employing several, wavelength-complementary photocatalysts we aimed at providing a more efficient use of the energy of polychromatic light.

To couple formate oxidation to photocatalytic $\mathrm{H}_{2} \mathrm{O}_{2}$ generation, we envisioned an enzymatic relay system comprising formate dehydrogenase from Candida boidinii $(\mathrm{Cb} \mathrm{FDH})$ to mediate the hydride transfer from formate to $\mathrm{NAD}^{+}{ }^{19}$ The resulting NADH has previously been shown to be prone to photocatalytic, aerobic oxidation yielding $\mathrm{H}_{2} \mathrm{O}_{2}$ (Scheme 1). ${ }^{20-22}$ The peroxygenase used in this study was the recombinant, evolved peroxygenase from Agrocybe aegerita (rAaeUPO). ${ }^{23,24}$

First, we screened 23 commercially available dyes for their capability of oxidizing $\mathrm{NADH}$ and delivering the reducing equivalents to $\mathrm{O}_{2}$ to yield $\mathrm{H}_{2} \mathrm{O}_{2}$ (Table S1). Out of these, 17 were discarded either because they did not oxidize $\mathrm{NADH}$ or because their reduced form was stable in the presence of $\mathrm{O}_{2}$ and therefore unsuitable for the aim of this study.

The remaining candidates (all acridine derivatives) were investigated further with respect to their activity in photochemical NADH oxidation and $\mathrm{H}_{2} \mathrm{O}_{2}$ generation. The catalytic

Received: September 18, 2018

Revised: December 10, 2018

Published: December 18, 2018 
Scheme 1. Proposed Photoenzymatic System for in Situ Generation of $\mathrm{H}_{2} \mathrm{O}_{2}$ To Promote Peroxygenase-Catalyzed Hydroxylation Reactions

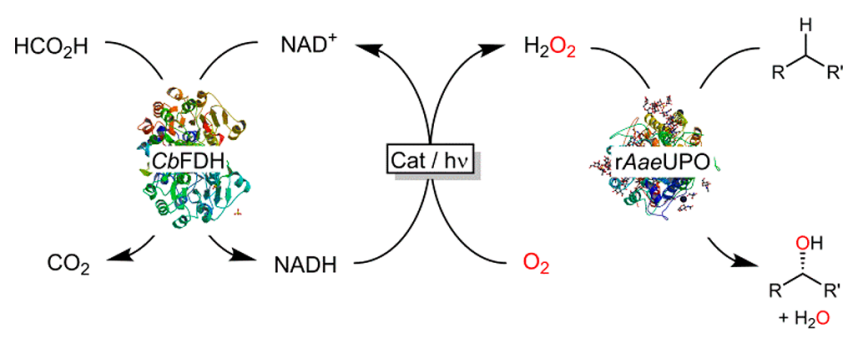

Table 1. Comparison of the $\mathrm{H}_{2} \mathrm{O}_{2}$ Formation Rates of Selected Acridine Derivatives in the Photochemical Oxidation of $\mathrm{NADH}^{a}$

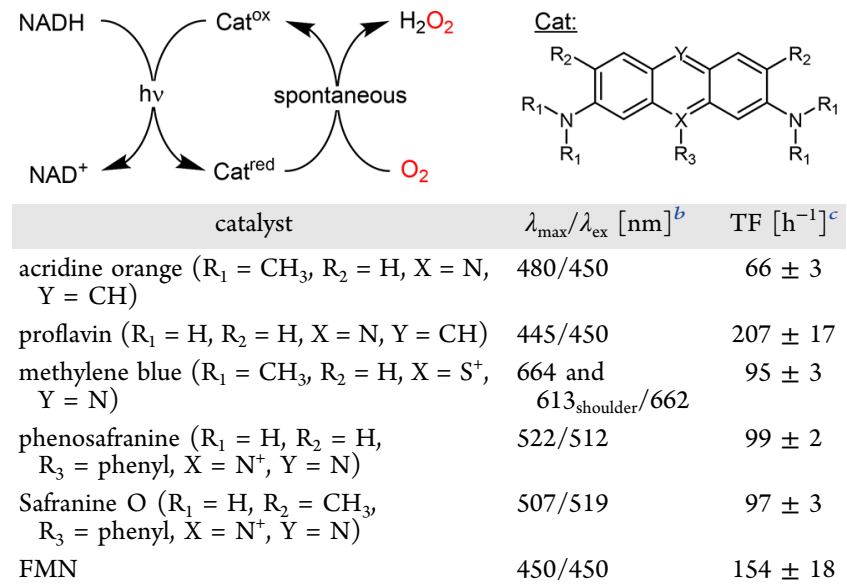

${ }^{a}$ General conditions: $50 \mu \mathrm{M}$ catalysts, $50 \mathrm{mM} \mathrm{KPi}, \mathrm{pH} 7.0,1 \mathrm{mM}$ $\mathrm{NADH}, 30{ }^{\circ} \mathrm{C}, 300 \mathrm{rpm} .{ }^{b} \lambda_{\max }=$ wavelength exhibiting the maximal photoabsortion; $\lambda_{\mathrm{ex}}=$ wavelength of the LED light source used for photoexcitation. ${ }^{c} \mathrm{TF}=$ turnover frequency of the catalyst $=\left(\mathrm{H}_{2} \mathrm{O}_{2}\right.$ formation rate) $\left[\mathrm{mM} \mathrm{h}^{-1}\right] /$ (concentration of the photocatalyst) $[\mathrm{mM}]$.

performance (expressed as turnover frequency, TF) of the photocatalysts is shown in Table 1 .

Drawing correlations between the physicochemical and structural properties of the photocatalysts and their activity (Table 1) is difficult as factors such as redox potential, photoexcitability, and reactivity of the reduced form with $\mathrm{O}_{2}$ contribute to the macroscopically observed $\mathrm{H}_{2} \mathrm{O}_{2}$ generation rate. Future work will aim at an in-depth understanding of the influence of the substitution pattern on aspects such as reactivity and stability of the photocatalysts.

Even though all photocatalysts mentioned in Table 1 were suitable to promote the rAaeUPO-catalyzed hydroxylation reaction, we focused on phenosafranine, methylene blue, and FMN, because this combination offers a broad coverage of the visible light spectrum (Figure 1). Additionally, as permanent ions, these photocatalysts ensure high and $\mathrm{pH}$-independent solubility in the aqueous reaction mixture.

Using these photocatalysts, either individually or in combination, together with the $\mathrm{CbFDH} / \mathrm{NAD} / \mathrm{HCO}_{2} \mathrm{H}$ system generated $\mathrm{H}_{2} \mathrm{O}_{2}$ to promote the rAaeUPO-catalyzed stereospecific hydroxylation of ethylbenzene to (R)-1-phenylethanol (Figure 2).

In the absence of either photocatalyst or rAaeUPO, no product formation was observed. The same is true for

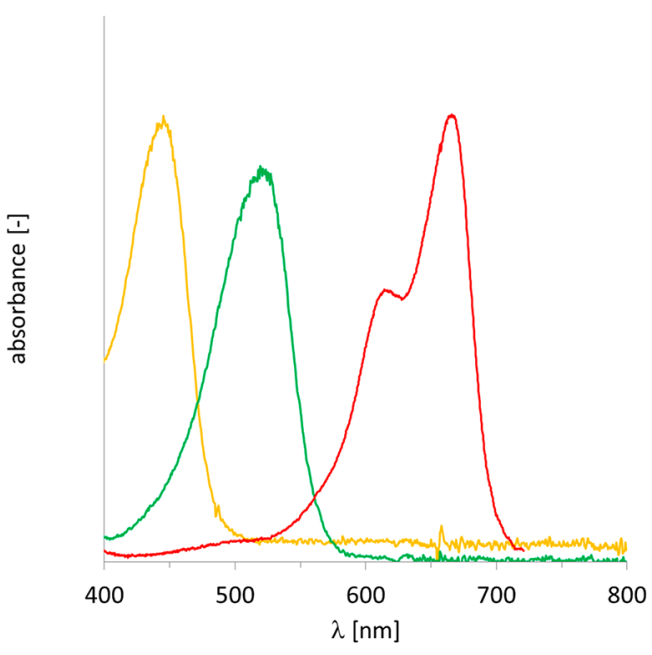

Figure 1. Coverage of the visible light spectrum by combining flavin mononucleotide (orange), phenosafranine (green), and methylene blue (red).
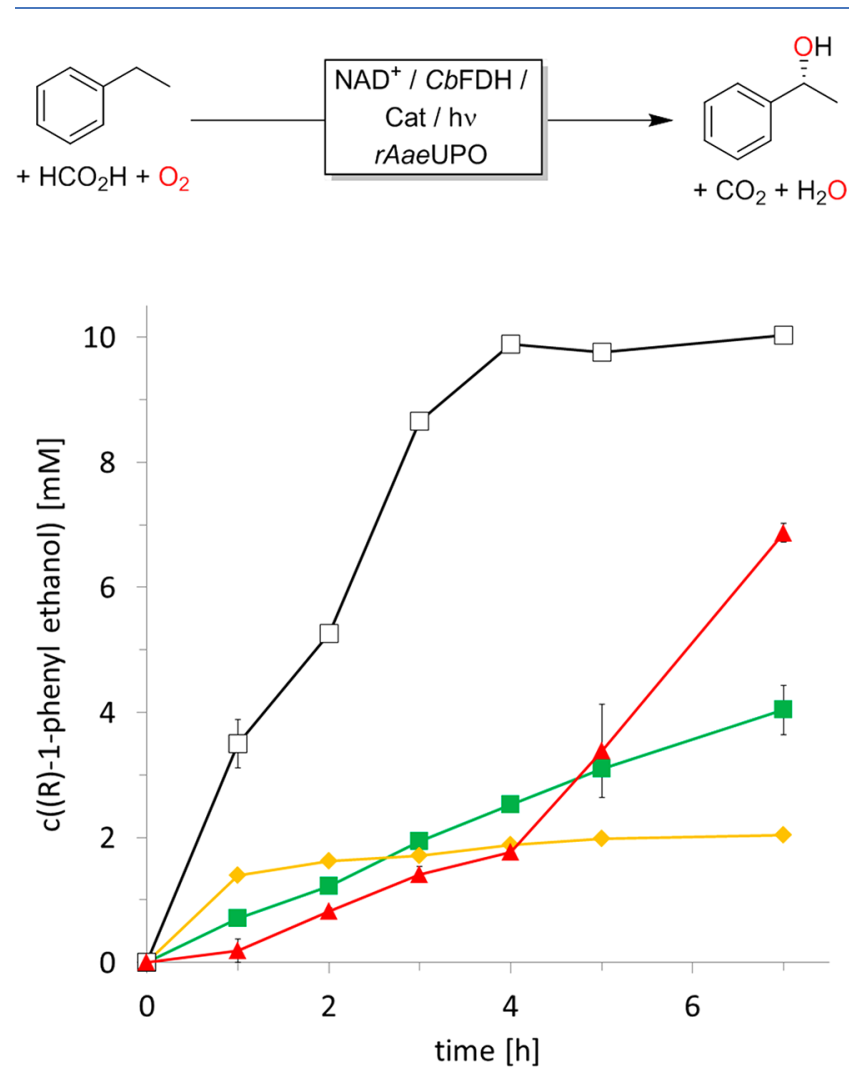

Figure 2. Photoenzymatic hydroxylation of ethylbenzene to (R)-1phenylethanol using $5 \mu \mathrm{M}$ FMN (orange $\downarrow$ ), $10 \mu \mathrm{M}$ methylene blue (red $\boldsymbol{\Delta}$ ), $5 \mu \mathrm{M}$ phenosafranine (green $\mathbf{\square}$ ), or $10 \mu \mathrm{M}$ methylene blue $+5 \mu \mathrm{M}$ phenosafranine $+5 \mu \mathrm{M}$ FMN $(\square)$ as photocatalysts. Conditions: $\mathrm{c}(\mathrm{rAaeUPO})=100 \mathrm{nM}, \mathrm{c}(\mathrm{CbFDH})=4.8 \mu \mathrm{M}, \mathrm{c}\left(\mathrm{NAD}^{+}\right)$ $=0.4 \mathrm{mM}, \mathrm{c}\left(\mathrm{NaHCO}_{2}\right)=75 \mathrm{mM}, \mathrm{c}($ ethylbenzene $)=10 \mathrm{mM}, 50 \mathrm{mM}$ $\mathrm{KPi}$ buffer ( $\mathrm{pH} 7,0.8 \% \mathrm{MeOH}(\mathrm{v} / \mathrm{v})), T=30^{\circ} \mathrm{C}, \lambda=450,520$, and $630 \mathrm{~nm}$ (blue, green, and red LED light). Please note: using a broadspectrum (sunlight-imitating) light source (Lightincure LC8 L9566, Hamamatsu) gave comparable results (Figure S9).

experiments performed in the darkness with the exception of methylene blue where upon prolonged reaction times some product traces were found $(0.4 \mathrm{mM}$ after $48 \mathrm{~h})$. This is in line with previous observations that methylene blue is capable of a 
A
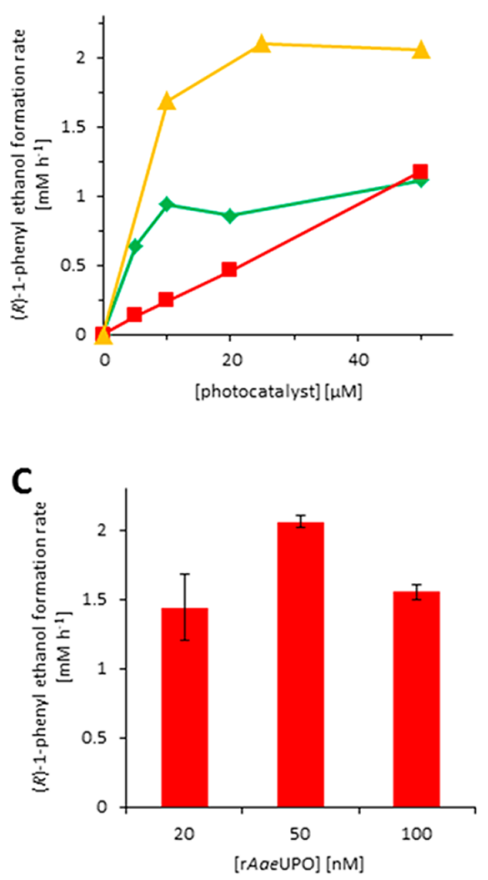

E

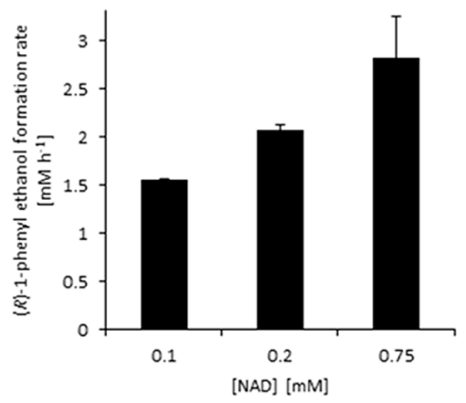

B
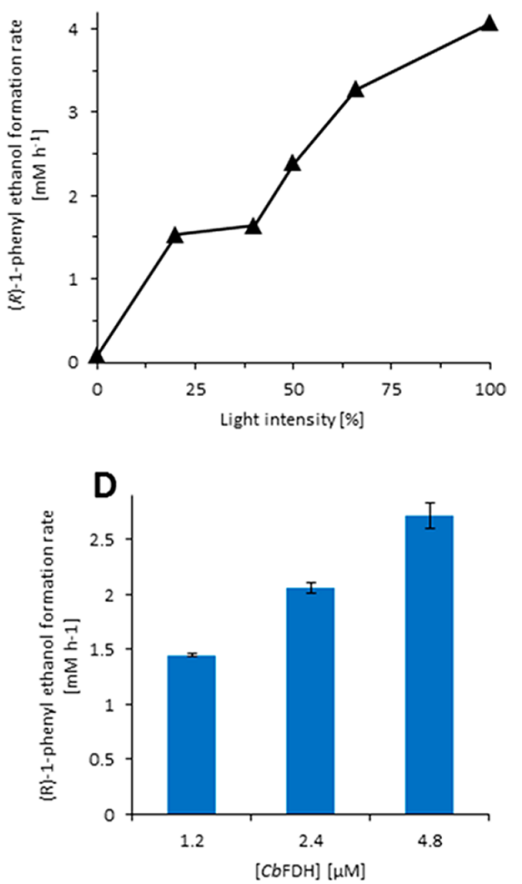

Figure 3. Influence of different reaction parameters on the product formation rate of the photoenzymatic hydroxylation of ethylbenzene. (A) Concentration of the photocatalyst (red $\mathbf{\square}$ : methylene blue; green $\$$ : phenosafranine; orange $\mathbf{\Delta}$ : FMN); (B) intensity of broadband light source $\left(\mathrm{c}(\mathrm{rAae} \mathrm{UPO})=100 \mathrm{nM}, \mathrm{c}(\mathrm{CbFDH})=4.8 \mu \mathrm{M}, \mathrm{c}\left(\mathrm{NAD}^{+}\right)=0.4 \mathrm{mM}\right)$; concentration of rAaeUPO $(\mathrm{C}), \mathrm{CbFDH}(\mathrm{D})$, or NAD ${ }^{+}(\mathrm{E})$. Conditions (unless indicated otherwise): $\mathrm{c}(\mathrm{rAae} \mathrm{UPO})=50 \mathrm{nM}, \mathrm{c}(\mathrm{CbFDH})=2.4 \mu \mathrm{M}, \mathrm{c}\left(\mathrm{NAD}^{+}\right)=0.2 \mathrm{mM}, \mathrm{c}\left(\mathrm{NaHCO}_{2}\right)=75 \mathrm{mM}, \mathrm{c}($ ethylbenzene $)=10$ $\mathrm{mM}, 50 \mathrm{mM}$ KPi buffer $(\mathrm{pH} 7,0.8 \% \mathrm{MeOH}(\mathrm{v} / \mathrm{v})), \mathrm{T}=30^{\circ} \mathrm{C}$.

"dark-reaction" with $\mathrm{NADH} .^{21,25}$ Some product formation (approximately 5-20\% of the "normal" product formation rate) was observed in the absence of either component of the $\mathrm{NADH}$ regeneration system (i.e., in the absence of formate, $\mathrm{Cb} \mathrm{FDH}$, or $\left.\mathrm{NAD}^{+}\right)$. The latter observation most likely can be attributed to an undesired reductive quenching of the excited photocatalysts by oxidizable components in the reaction mixture (i.e., proteins, amino acids, etc.; see also Tables S2 and S3). ${ }^{26}$ It is worth mentioning that the optical purity of the product always exceeded $95 \%$ enantiomeric excess (ee).

The relative rates observed with the individual photocatalysts qualitatively corresponded to the photocatalytic $\mathrm{H}_{2} \mathrm{O}_{2}$ generation rates shown in Table 1 . Noteworthy, when using a combination of the single photocatalysts, the product formation rate was approximately the sum of the previously observed individual rates (Figure 2). The turnover numbers calculated for the catalytic components (rAaeUPO, photocatalysts, $\mathrm{NAD}$, and $\mathrm{CbFDH}$ ) were $100000,500,25$, and 1785, respectively.
Next, we further examined the influence of different reaction parameters on the rate of the photoenzymatic hydroxylation reaction in more detail (Figure 3). Quite expectedly, the concentration of the photocatalysts directly influenced the rate of the overall system (Figure 3A). While this correlation was linear with methylene blue over the entire concentration range investigated, a saturation-type behavior was observed with phenosafranine and FMN, which most likely can be attributed to the decreasing optical transparency of the reaction mixture at elevated concentrations of the latter photocatalysts. The overall reaction rate also directly correlated with the intensity of the light source (Figure 3B).

Varying the concentration of either $\mathrm{NAD}^{+}$(Figure 3E) or $\mathrm{Cb}$ FDH (Figure 3D) directly influenced the reaction rate while the concentration of rAaeUPO (Figure 3C) had no clear influence.

Overall, we conclude that the photochemical oxidation of $\mathrm{NADH}$ (being influenced by the in situ concentration of $\mathrm{NADH}$ and the concentration of the photoexcited photo- 
catalyst(s)) was overall rate-limiting under the conditions investigated.

Interestingly, with methylene blue, an acceleration of the reaction rate was observed over time (Figure 2). This acceleration could be assigned to a photochemical activation of the photocatalyst as a similar observation was made upon preincubation of methylene blue alone by red light (Figure S6); blue light did not induce this acceleration. Currently, we are lacking a plausible explanation for this activation effect, and further studies will be necessary to understand (and synthetically exploit) this observation.

One major challenge observed, especially using FMN as photocatalyst (Figure $2 \boldsymbol{V}$ ), was the poor long-term stability of the overall reaction. Particularly, the NADH regeneration reaction was impaired (Figure S7). We therefore investigated the stability of $\mathrm{CbFDH}$ in the presence of the photocatalysts upon illumination (Figure 4).

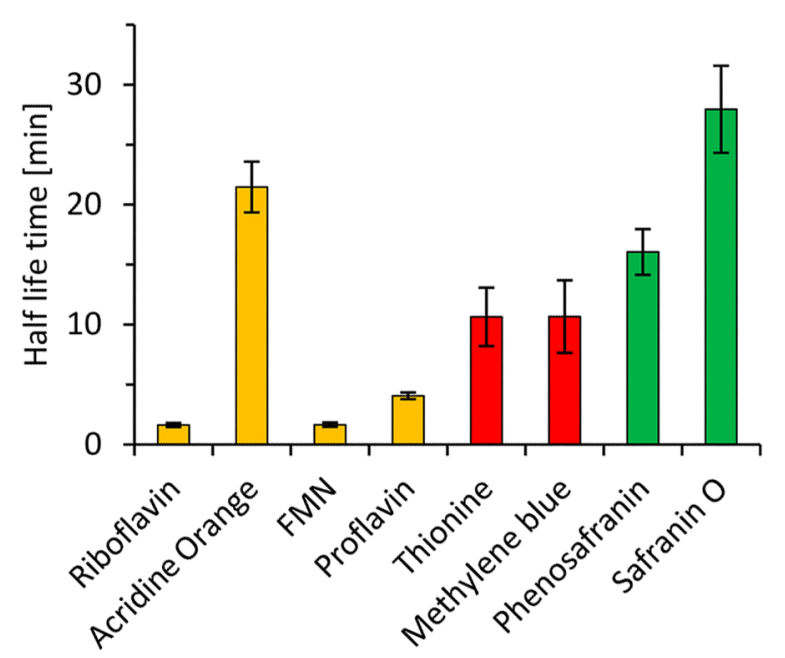

Figure 4. Stability of $\mathrm{CbFDH}$ in the presence of some photocatalysts upon illumination. General conditions: $2.4 \mu \mathrm{M} \mathrm{CbFDH}, 50 \mu \mathrm{M}$ photocatalysts, $50 \mathrm{mM} \mathrm{KPi}$ buffer, $\mathrm{pH}$ 7, $300 \mathrm{rpm}, 30{ }^{\circ} \mathrm{C}$. For comparison, the half-life time of $\mathrm{CbFDH}$ in the presence of the photocatalysts but under dark conditions was $433 \mathrm{~min}$.

Especially, the flavin derived photocatalysts rapidly inactivated $\mathrm{CbFDH}$. Most probably, this occurred due to oxidative modification of surface-bound amino acids leading to enzyme inactivation/denaturation. Further experiments identifying the amino acids involved are currently ongoing. On the basis of this, $\mathrm{CbFDH}$ mutants exhibiting increased robustness in the presence of the exited photocatalysts can be conceived. Also, physical separation of photocatalysts and $\mathrm{CbFDH}$ may represent a solution to this inactivation issue. In similar cases, this strategy resulted in significant stabilizations of the overall reaction. ${ }^{27-30}$

Another issue of the photoenzymatic reaction system may be the well-known photobleaching of the organic photocatalysts. ${ }^{31,32}$ Particularly, the flavin-based photocatalysts exhibited a rather modest stability upon illumination with $450 \mathrm{~nm}$ (Figure 5). Safranine derivatives excelled in this respect by more than 100-fold longer half-life times as compared to, e.g., FMN.

These findings also were confirmed in photoenzymatic reactions using FMN, phenosafranine, or methylene blue, respectively (Table 2). Compared to the first, the latter two

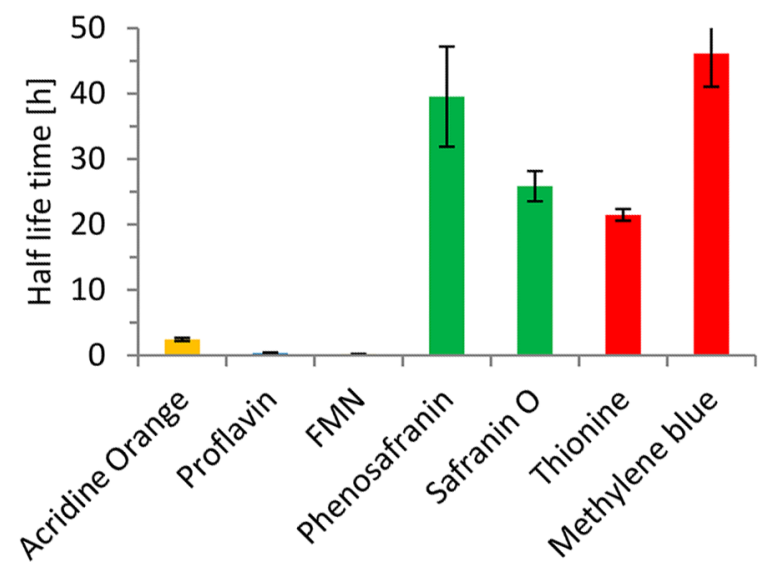

Figure 5. Stability of the photocatalysts upon illumination. General conditions: $100 \mu \mathrm{M}$ photocatalysts, $50 \mathrm{mM} \mathrm{KPi}$ buffer, $\mathrm{pH}$ 7, 300 rpm, $30^{\circ} \mathrm{C}$.

Table 2. Comparison of the Turnover Numbers (TON) of the Different Catalysts ${ }^{a}$

$\begin{array}{lccc} & \text { photocatalyst } & r A a e \text { UPO } & C b \text { FDH } \\ \text { FMN } & 649 & 6490 & 135 \\ \text { phenosafranine } & 2500 & 25000 & 520 \\ \text { methylene blue } & 3992 & 39920 & 832\end{array}$

${ }^{a}$ Conditions: $\mathrm{c}(\mathrm{rAaeUPO})=100 \mathrm{nM}, \mathrm{c}(\mathrm{CbFDH})=4.8 \mu \mathrm{M}$, $\mathrm{c}\left(\mathrm{NAD}^{+}\right)=0.4 \mathrm{mM}, \mathrm{c}\left(\mathrm{NaHCO}_{2}\right)=75 \mathrm{mM}, \mathrm{c}($ ethylbenzene $)=10$ $\mathrm{mM}, \mathrm{c}$ (photocatalyst) $=1 \mu \mathrm{M}, 50 \mathrm{mM} \mathrm{KPi}$ buffer $(\mathrm{pH} 7,0.8 \% \mathrm{MeOH}$ $(\mathrm{v} / \mathrm{v})), T=30^{\circ} \mathrm{C}$, polychromatic light source.

gave significantly higher turnover numbers for all catalysts employed.

Overall, we have demonstrated that simple electron donors such as formate can drive peroxygenase-catalyzed oxyfunctionalization reactions. Furthermore, in this study, we have demonstrated that a more efficient usage of the visible light spectrum is possible by combining complementary photocatalysts.

Admittedly, this system still is far from preparative applicability. Especially, the robustness of the formate dehydrogenase used represents a practical limitation, which may be overcome by evaluating FDHs from other sources or $\mathrm{CbFDH}$ mutants with improved resistance. Nevertheless, it should be noted that despite the early stage of development the proposed reaction scheme already compares well with the state-of-the-art system.

We are convinced that with this study we are paving the way toward more efficient photoenzymatic reaction schemes.

\section{ASSOCIATED CONTENT}

\section{Supporting Information}

The Supporting Information is available free of charge on the ACS Publications website at DOI: 10.1021/acscatal.8b03752.

Complete description of the experimental and analytical procedures as well as some additional results (PDF)

\section{AUTHOR INFORMATION}

\section{Corresponding Author}

*E-mail: f.hollmann@tudelft.nl.

ORCID $\odot$

Miguel Alcalde: 0000-0001-6780-7616 
Chan Beum Park: 0000-0002-0767-8629

Frank Hollmann: 0000-0003-4821-756X

\section{Notes}

The authors declare no competing financial interest.

\section{ACKNOWLEDGMENTS}

We thank The Netherlands Organisation for Scientific Research for financial support through a VICI grant (No. 724.014.003).

\section{REFERENCES}

(1) Wang, Y.; Lan, D.; Durrani, R.; Hollmann, F. Peroxygenases en route to becoming dream catalysts. What are the opportunities and challenges? Curr. Opin. Chem. Biol. 2017, 37, 1-9.

(2) Hofrichter, M.; Ullrich, R. Oxidations catalyzed by fungal peroxygenases. Curr. Opin. Chem. Biol. 2014, 19, 116-125.

(3) Dong, J.; Fernández-Fueyo, E.; Hollmann, F.; Paul, C.; Pesic, M.; Schmidt, S.; Wang, Y.; Younes, S.; Zhang, W. Biocatalytic oxidation reactions - a Chemist's perspective. Angew. Chem., Int. Ed. 2018, 57, 9238-9261.

(4) Lutz, S.; Steckhan, E.; Liese, A. First asymmetric electroenzymatic oxidation catalyzed by a peroxidase. Electrochem. Commun. 2004, 6, 583-587.

(5) Bankar, S. B.; Bule, M. V.; Singhal, R. S.; Ananthanarayan, L. Glucose oxidase - An overview. Biotechnol. Adv. 2009, 27, 489-501.

(6) Ni, Y.; Fernández-Fueyo, E.; Baraibar, A. G.; Ullrich, R.; Hofrichter, M.; Yanase, H.; Alcalde, M.; van Berkel, W. J. H.; Hollmann, F. Peroxygenase-catalyzed oxyfunctionalization reactions promoted by the complete oxidation of methanol. Angew. Chem., Int. Ed. 2016, 55, 798-801.

(7) Pesic, M.; Willot, S. J.-P.; Fernández-Fueyo, E.; Tieves, F.; Alcalde, M.; Hollmann, F. Multienzymatic in situ hydrogen peroxide generation cascade for peroxygenase-catalysed oxyfunctionalisation reactions. Z. Naturforsch., C: J. Biosci. 2018, DOI: 10.1515/znc-20180137.

(8) Pereira, P. C.; Arends, I.; Sheldon, R. A. Optimizing the chloroperoxidase-glucose oxidase system: The effect of glucose oxidase on activity and enantioselectivity. Process Biochem. 2015, 50, 746-751.

(9) Holtmann, D.; Krieg, T.; Getrey, L.; Schrader, J. Electroenzymatic process to overcome enzyme instabilities. Catal. Commun. 2014, 51, 82-85.

(10) Getrey, L.; Krieg, T.; Hollmann, F.; Schrader, J.; Holtmann, D. Enzymatic halogenation of the phenolic monoterpenes thymol and carvacrol with chloroperoxidase. Green Chem. 2014, 16, 1104-1108.

(11) Krieg, T.; Huttmann, S.; Mangold, K.-M.; Schrader, J.; Holtmann, D. Gas diffusion electrode as novel reaction system for an electro-enzymatic process with chloroperoxidase. Green Chem. 2011, 13, 2686-2689.

(12) Horst, A. E. W.; Bormann, S.; Meyer, J.; Steinhagen, M.; Ludwig, R.; Drews, A.; Ansorge-Schumacher, M.; Holtmann, D. Electro-enzymatic hydroxylation of ethylbenzene by the evolved unspecific peroxygenase of Agrocybe aegerita. J. Mol. Catal. B: Enzym. 2016, 133, S137-S142.

(13) Zhang, W.; Fernández-Fueyo, E.; Ni, Y.; van Schie, M.; Gacs, J.; Renirie, R.; Wever, R.; Mutti, F. G.; Rother, D.; Alcalde, M.; Hollmann, F. Selective aerobic oxidation reactions using a combination of photocatalytic water oxidation and enzymatic oxyfunctionalizations. Nat. Catal. 2018, 1, 55-62.

(14) Zhang, W.; Burek, B. O.; Fernández-Fueyo, E.; Alcalde, M.; Bloh, J. Z.; Hollmann, F. Selective activation of C-H bonds by cascading photochemistry with biocatalysis. Angew. Chem., Int. Ed. 2017, 56, 15451-15455.

(15) Choi, D. S.; Ni, Y.; Fernández-Fueyo, E.; Lee, M.; Hollmann, F.; Park, C. B. Photoelectroenzymatic Oxyfunctionalization on FlavinHybridized Carbon Nanotube Electrode Platform. ACS Catal. 2017, 7, 1563-1567.
(16) Churakova, E.; Arends, I. W. C. E.; Hollmann, F. Increasing the Productivity of Peroxidase-Catalyzed Oxyfunctionalization: A Case Study on the Potential of Two-Liquid-Phase Systems. ChemCatChem 2013, 5, 565-568.

(17) Churakova, E.; Kluge, M.; Ullrich, R.; Arends, I.; Hofrichter, M.; Hollmann, F. Specific photobiocatalytic oxyfunctionalization reactions. Angew. Chem., Int. Ed. 2011, 50, 10716-10719.

(18) Perez, D. I.; Mifsud Grau, M.; Arends, I. W. C. E.; Hollmann, F. Visible light-driven and chloroperoxidase-catalyzed oxygenation reactions. Chem. Commun. 2009, 6848-6850.

(19) Popov, V. O.; Lamzin, V. S. NAD+-dependent formate dehydrogenase. Biochem. J. 1994, 301, 625-643.

(20) Rauch, M.; Schmidt, S.; Arends, I. W. C. E.; Oppelt, K.; Kara, S.; Hollmann, F. Photobiocatalytic alcohol oxidation using LED light sources. Green Chem. 2017, 19, 376-379.

(21) Kochius, S.; Ni, Y.; Kara, S.; Gargiulo, S.; Schrader, J.; Holtmann, D.; Hollmann, F. Light-Accelerated Biocatalytic Oxidation Reactions. ChemPlusChem 2014, 79, 1554-1557.

(22) Gargiulo, S.; Arends, I. W. C. E.; Hollmann, F. A Photoenzymatic System for Alcohol Oxidation. ChemCatChem 2011, 3, 338-342.

(23) Molina-Espeja, P.; Garcia-Ruiz, E.; Gonzalez-Perez, D.; Ullrich, R.; Hofrichter, M.; Alcalde, M. Directed Evolution of Unspecific Peroxygenase from Agrocybe aegerita. Appl. Environ. Microbiol. 2014, 80, 3496-3507.

(24) Ullrich, R.; Nüske, J.; Scheibner, K.; Spantzel, J.; Hofrichter, M. Novel haloperoxidase from the agaric basidiomycete Agrocybe aegerita oxidizes aryl alcohols and aldehydes. Appl. Environ. Microbiol. 2004, $70,4575-4581$.

(25) Könst, P.; Kara, S.; Kochius, S.; Holtmann, D.; Arends, I. W. C. E.; Ludwig, R.; Hollmann, F. Expanding the Scope of LaccaseMediator Systems. ChemCatChem 2013, 5, 3027-3032.

(26) Frisell, W. R.; Chung, C. W.; Mackenzie, C. G. Catalysis of Oxidation of Nitrogen Compounds by Flavin Coenzymes in the Presence of Light. J. Biol. Chem. 1959, 234, 1297-1302.

(27) Hildebrand, F.; Lütz, S. Stable Electroenzymatic Processes by Catalyst Separation. Chem. - Eur. J. 2009, 15, 4998-5001.

(28) Rudroff, F.; Mihovilovic, M. D.; Gröger, H.; Snajdrova, R.; Iding, H.; Bornscheuer, U. T. Opportunities and challenges for combining chemo- and biocatalysis. Nature Catal. 2018, 1, 12-22.

(29) Sato, H.; Hummel, W.; Gröger, H. Cooperative Catalysis of Noncompatible Catalysts through Compartmentalization: Wacker Oxidation and Enzymatic Reduction in a One-Pot Process in Aqueous Media. Angew. Chem., Int. Ed. 2015, 54, 4488-4492.

(30) Zhang, W.; Fernandez Fueyo, E.; Hollmann, F.; Leemans Martin, L.; Pesic, M.; Wardenga, R.; Höhne, M.; Schmidt, S. Combining Photo-Organo Redox- and Enzyme Catalysis Facilitates Asymmetric C-H Bond Functionalization. Eur. J. Org. Chem. 2018, DOI: $10.1002 /$ ejoc.201801692.

(31) Insinska-Rak, M.; Golczak, A.; Sikorski, M. Photochemistry of Riboflavin Derivatives in Methanolic Solutions. J. Phys. Chem. A 2012, 116, 1199-1207.

(32) Holzer, W.; Shirdel, J.; Zirak, P.; Penzkofer, A.; Hegemann, P.; Deutzmann, R.; Hochmuth, E. Photo-induced degradation of some flavins in aqueous solution. Chem. Phys. 2005, 308, 69-78. 